Impact Factor 5.244

Index Copernicus Value: 5.88

ISSN (e)-2347-176x ISSN (p) 2455-0450

crossref DOI: _http://dx.doi.org/10.18535/jmscr/v4i4.56

Journal Of Medical Science And Clinical Research

\title{
A Study to Determine the Profile of Type 2 Diabetes Mellitus in Patients Attending Bokaro General Hospital (Bokaro)
}

\author{
Authors \\ Dr Avnish Kumar Singh (DNB General Medicine), Dr S.K Sinha (DM Endocrinology) \\ Dr Aviral Shah (MD Medicine) \\ Bokaro General Hospital
}

\begin{abstract}
Aims and objective: Prime objective was to determine anthropometric, clinical, biochemical profile of type 2 diabetes mellitus in patients attending Bokaro General Hospital.

Method: A hospital based cross sectional study was conducted during March 2010 to June 2012. The study population comprised diabetic subjects attending endocrinology unit of Bokaro General Hospital. Total 126 patients were taken comprising of old and new cases.After taking and recording detailed history including present complains ,past history including duration of diabetes, history and duration of hypertension, cardiovascular disease, dyslipidemia; personal history and complete anthropometric and physical examination was carried out.

Result : Out of 126 patients about $4 \%$ were $<40$ years of age, maximum number of patient belonged to age

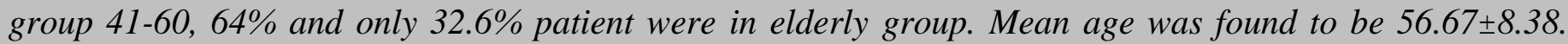
Majority of females fell in the age group of $41-60$ years (76.59\%). Whereas age distribution was almost equal in men and women in 41-60.In both male and female age group only 2.53\%,6.38\% were noted to be $<40$ years of age respectively. $p$ value $=<.001$, Which is statistically significant. The difference between male and female was found to be highly significant $(p<0.001)$ Around $28.58 \%$ patient were non obese .In our study majority of patient were found to be obese (50\%) and $21.42 \%$ were observed to be overweight. Most of our patient were found to be obese (with BMI 25.22 3.73 ) according to the WHO guidelines and the consensus statement for diagnosis of Obesity, Abdominal obesity and the metabolic syndrome for Asian Indians. (Normal BMI: 18-22.9 kg/m2; Overweight: 22-24.9 kg/m2;Obesity: >25 kg/m2). Most of the patients were obese. Overweight patient constituted $26.65 \%$ male and $12.76 \%$ female. Almost equal number of diabetic males (27.58\%) as well as females(29.78\%) were having normal BMI. $p$ value $<0.04$. The difference between male and female was found to be significant ( $p<0.04)$. Male patient having central obesity $(55 \%)$ exceeded males with normal (45\%) abdominal circumference. In females majority of them were having central obesity and only $6 \%$ females were having normal abdominal girth. Mean waist circumference among females was $92.03 \pm 9.85$. In comparison more than $90 \%$ of female were found to be having central obesity, whereas about half (55\%) of males revealed abdominal obesity.Good number of males (45\%) were normal around the waist .only $6.38 \%$ female were having normal abdominal girth. $p$ value <.001. The difference between male and female was found to be highly significant $(p<0.001)$.

More than half (55\%) of our population were having cholesterol within normal limit.
\end{abstract}


Around $60 \%$ of diabetic patient revealed normal triglyceride level. Only $41 \%$ diabetic showed raised triglyceride level. Out of 126 patients very few diabetics(15\%) were having normal HDl. Majority were having low HDL. LDL was well within control in $86 \%$ of patients with 82 out of 126 patients LDL less than/equal to $100 \mathrm{mg} / \mathrm{dl}$. About $69 \%$ of total diabetic were suffering from hypertension. Significant percentage of females were found to be having dyslipidemia (91\%), whereas about $79 \%$ of males were having abnormal lipid profile. The difference between male and female was found to be significant $(p<0.03)$. In our study it was observed that approximately $70 \%$ of patients were having Metabolic syndrome and on comparing between male to female percent it was seen that female patient were predominantly suffering from metabolic syndrome. The difference between male and female was found to be highly significant ( $p<0.001)$ Out of 126 patients 15 patients were having hypothyroidismIn present study good glycemic control was achieved in $34.17 \%$ of males but only $21.27 \%$ of females revealed good control .Equal number of male and females had glycated haemoglobin between 7-9\% More than 51\% of females and about $39 \%$ of males showed HbAlC above 9\%.p value 0.1. The difference between male and female was found to be not significant $(p<0.1)$.

Out of 126 patients $45.56 \%$ males and $44.68 \%$ females were having diabetic neuropathy Approximately one third (27\%) of males and twenty percent females had retinopathy. The difference between male and female was found to be not significant ( $p$ value 0.17). One fourth of males $26 \%$ and about one fifth of females had nephropathy. Kidney involvement was seen in only $23 \%$ of patients. The difference between male and female was found to be not significant (p value 0.3).In present study out of 126 patients $17 \%$ patient were suffering from coronary heart disease.

\section{Conclusion}

In our hospital study although conducted in small number of patients revealed:

1. Most of the patients belonged to age group 40-60.

2. Majority of diabetics were obese, having BMI more than $25 \mathrm{~kg} / \mathrm{m} 2$

3. Very few new patients were studied in our study presenting with polydipsia, polyuria as common presentation.

4. Majority of our patients were having dyslipidemia, and it was seen that dyslipidemia was significantly preponderant in females.

5. There was dominance of female having metabolic syndrome almost reaching $91 \%$ which is much above the findings depicted by other Indian studies, Probably because of limited number of females in our study.

6. Our study revealed the level of glycemic control was near the target given by ADA in almost one third of patients, which can be attributed to comprehensive care imparted by endocrinology unit.

7. Neuropathy, Retinopathy and Nephropatahy, were present in one fourth of the patient and it was seen to be significantly associated with duration of diabetes.

Further study with large number of patient is required to substantiate our study.

Significant Findings of the study

1. Most of the patients belonged to age group 40-60.

2. Majority of diabetics were obese, having BMI more than $25 \mathrm{~kg} / \mathrm{m} 2$.

3. Very few new patients were studied in our study presenting with polydipsia, polyuria as common presentation.

4. Majority of our patients were having dyslipidemia, and it was seen that dyslipidemia was significantly preponderant in females..

5. There was dominance of female having metabolic syndrome almost reaching $91 \%$ which is much above the findings depicted by other Indian studies, Probably because of limited number of females in our study.

6. Our study revealed the level of glycemic control was near the target given by ADA in almost one third of patients, which can be attributed to comprehensive care imparted by endocrinology unit.

7. Neuropathy, Retinopathy and Nephropatahy, were present in one fourth of the patient and it was seen to be significantly associated with duration of diabetes.

Further study with large number of patient is required to substantiate our study.

Keywords: Profile of Type 2 DM, Metabolic syndrome, hypertension 


\section{Introduction}

Diabetes mellitus is a group of metabolic diseases characterized by hyperglycemia resulting from defects in insulin secretion, insulin action, or both. The chronic hyperglycemia of diabetes is associated with long-term damage, dysfunction, and failure of various organs, especially the eyes, kidneys, nerves, heart, and blood vessels. India leads the world with largest number of diabetics. Also being termed as the Diabetic capital of World ${ }^{(1)}$. WHO predicts India will have highest number of diabetes patients by 2025 . It is the sixth leading cause of death and results in significant morbidity (2). According to recent estimates approximately 285 million people worldwide(6.6\%) in the $20-79$ years age group will have diabetes in 2010 and by 2030,438 million $(7.8 \%)$ of the adult population is expected to have diabetes the largest increase will take place in region dominated by developing countries.

The global increase in the prevalence of diabetes is due to population growth, aging, urbanization and increase of obesity and physical inactivity. The so called "Asian Indian Phenotype" refers to certain unique clinical and biochemical abnormalities in Indians which include increased insulin resistance, greater abdominal adiposity i.e., higher waist circumference despite lower body mass index, lower adiponectin and higher high sensitive C-reactive protein levels. This phenotype makes Asian Indians more prone to diabetes and premature coronary artery disease. At least a part of this is due to genetic factors. However, the primary driver of the epidemic of diabetes is the rapid epidemiological transition associated with changes in dietary patterns and decreased physical activity as evident from the higher prevalence of diabetes in the urban population. Even though the prevalence of microvascular complications of diabetes like retinopathy and nephropathy are comparatively lower in Indians, the prevalence of premature coronary artery disease is much higher in Indians compared to other ethnic groups. The most disturbing trend is the shift in age of onset of diabetes to a younger age in the recent years. This could have long lasting adverse effects on nation's health and economy.

Early identification of at-risk individuals using simple screening tools like the Indian Diabetes Risk Score (IDRS) and appropriate lifestyle intervention would greatly help in preventing or postponing the onset of diabetes and thus reducing the burden on the community and the nation as a whole. Recent studies from India showed increasing prevalence of type 2 diabetes in all the regions like $19.5 \%$ in Kerala (ADEPS), $15.5 \%$ in Chennai (CURES), $13.5 \%$ Chennai, $12.4 \%$ Bangalore, $16.6 \%$ hyderabad, $11.7 \%$ Kolkata and 9.3\% Mumbai (NUDS). In the urban population, an Indian Council of Medical Research (ICMR) study in 1972 reported a prevalence of $2.3 \%$ (Ahuja et al 1979) which rose to $12.1 \%$ in the year 2000 (Ramachandran et al. 2001). More recently, Mohan et al. (2008) provided estimates from a nationwide surveillance study of T2DM and found that in urban areas there was a prevalence $7.3 \%$ of known T2DM and a prevalence of $3.2 \%$ in periurban/slum areas (urban fringes). An early study in 1991 of rural areas in Delhi indicated that the prevalence rate for T2DM ranged from 0.4-1.5\% (Ahuja et al. 1991).

Prevalence rates vary according to measuring criteria used e.g. using the American diabetes association criteria, it has recently been estimated to be $1.9 \%$ in the rural areas; but with using the WHO criteria the estimate increased to $2.7 \%$ (Sadikot et al. 2004).Other studies indicate higher rates. Data from a large-scale survey on 4,535 individuals aged 30 years from 20 villages of Godavari, a developing rural area of Andhra Pradesh, suggests that rural India may soon experience the urban epidemic of T2DM (Chow et al. 2006) the prevalence for known T2DM was of $6.4 \%$, for undiagnosed $\mathrm{T} 2 \mathrm{DM} 6.8 \%$, and that $15.5 \%$ had Impaired fasting glucose. While these data are by no means representative of rural India as a whole,they imply increases of T2DM. Figures based on National Family Health Survey (NFHS) in 2005-06 .suggest the prevalence of T2DM in 
rural India are highest in Kerala, Tripura, West Bengal, Goa and Sikkim, (1500 to >2000 individuals per 100,000 individuals) and least in central India (<500individuals per 100,000 individuals). There has been a dramatic improvement of the Indian economy in terms of percapita income. These dramatic changes have had a great impact on urbanization and lifestyle of the Indians. Diabetes mellitus has become the main public-health problem and amenable to change through early recognition at the individual level and surveillance at the population level. Results of studies showed that India is facing three-fold rise in the prevalence of diabetes in urban $(5-15 \%)$ and inrural $(2-6 \%)$ areas ${ }^{(3,4)}$. India tops in the world with the largest number of diabetic subjects (31.7 million cases of T2DM) ${ }^{(5)}$. This is further compounded by the epidemic of obesity and doubling the cost of diabetes management. Therefore, prevention is important from monetary and from lifestyle modification point of view. Increasing awareness of risk factors and how to prevent these should be emphasized in the population ${ }^{(6)}$. Apart from this, the lifestyle modifications (physical exercise, diet control, etc.)are appropriate measures in the prevention of diabetes. Furthermore, to control and prevent the T2DM epidemic, it must be approached in an appropriate, socioeconomically and culturally-relevant manner but very little data are available from Jharkhand to support this, and for the prevention of diabetes, it is also vital to know the profile of diabetics. This paper reports the profile of type 2 diabetic in Bokaro. Scarcity of research in Jharkhand, only one pilot study by Ramchandra et al. Present study has been taken up, to determine the profile of type 2 diabetes mellitus patient attending BGH, BOKARO. Both indoor as well as outdoor patient of type 2 diabetes were included.

\section{Methods}

A hospital based cross sectional study was conducted during March 2010 to June 2012 in Bokaro General Hospital, Bokaro district in state of Jharkhand. Bokaro is an Industrial Town .It is famous for its steel plant SAIL.

\section{Exclusion criteria}

1. Diabetic with Cancer patients

2. Diabetic with cld

3. Type $1 \mathrm{dm}$

4. Gdm

The study population comprised diabetic subjects attending endocrinology unit of Bokaro General Hospital. Total 126 patients were taken comprising of old and new cases. Informed consent (written consent from literate subjects and verbally informed consent from illiterate subjects), 126 subjects were enrolled through simple randomsampling method. After explaining the details of the study, a comprehensive case history was recorded on a semi-structured, close-ended proforma. Basic data on age, sex, education, occupation. All the subjects were also interviewed regarding history of hypertension and other co-morbid conditions. A general physical examination was performed. After taking and recording detailed history including present complains ,past history including, duration of diabetes ,history and duration of hypertension, cardiovascular disease, dyslipidemia; personal history and complete anthropometric and physical examination was carried out-

1. Age

2. Sex

3. Height(Measure without shoes using a tape stadiometer)

4. Weight (measured with light clothing and without shoes on a portable weighing scale)

5. BMI (Calculated by dividing weight(in $\mathrm{kg}$ )by height squared (metre)]

6. Waist circumference (Waist circumference was measured just above the iliac crest using flexible measuring Tape)

\section{Physical examination}

Blood pressure was recorded after the subjects had rested for at least five minutes. Two readings were 
taken five minutes apart, and mean of the two was considered the actual blood pressure. Hypertension was diagnosed based on drug treatment for hypertension or if the blood pressure was $>130 / 80 \mathrm{mmHg}$ according to the Joint National Committee- 7 (JNC-VII) criteria (16-17). The diagnosis of new diabetes mellitus was made using the criteria established by the American Diabetes Association i.e. a medical record fulfilling following criteria

Criteria for the diagnosis of diabetes (ADA 2011)

A1C _6.5\%. The test should be performed in a laboratory using a method that is NGSP certified and standardized to the DCCT assay.*

Or

FPG _126 mg/dl (7.0 mmol/l). Fasting is defined as no caloric intake for at least 8 h.*

Or

2-h plasma glucose _200 mg/dl (11.1mmol/l) during an OGTT. The test should be

performed as described by the World Health Organization, using a glucose load containing the equivalent of $75 \mathrm{~g}$ anhydrous glucose dissolved in water.*

Or

In a patient with classic symptoms of hyperglycemia or hyperglycemic crisis, a random plasma glucose _200 mg/dl (11.1 mmol/l)

*In the absence of unequivocal hyperglycemia, result should be confirmed by repeat testing.

The guidelines of the National Cholesterol Education Programme were used for defining dyslipidaemia (19). It was defined by presence of one or more than one abnormal serum lipid concentration, such as hypercholesterolaemia, high LDL-C, hypertriglyceridaemia, and low HDL-C. Body massindex (BMI) values were defined according to the recommendations of the Indian Council of Medical Research for Indians. A study subject was considered to be obese if BMI was $\geq 25 \mathrm{~kg} / \mathrm{m} 2$ and overweight when BMI was 23-24.9 $\mathrm{kg} / \mathrm{m} 2$ (20). The criterion for glycaemic status was $<7 \%$ (good control), 7-9\% (sub-optimal control) $>9 \%$ (uncontrolled) (21).
These patients were then subjected to comprehensive laboratory investigation. Blood samples were drawn between 7:00 AM and 9:AM after 8-12 hours of overnight fasting.

OLYMPUS AU 640 autoanalyser was used to perform following test: -

1. Fasting blood glucose- Sample was collected in fluoride vial. Glucose was estimated using hexokinase method enzymatic UV test. Glucose is phosphorylated by hexokinase in the presence of atp and magnesium ion .To produce Glucose 6 Phosphate and ADP.G6PD specifically oxidizes G6 Phosphate to Gluconate 6 phosphate with concurrent reduction of NAD+ TO NADH by increase in absorbance at $340 \mathrm{~nm}$ is proportional to the glucose concentration in the sample.

2. Glycosylated Haemoglobin (HbA1c) :The concentration of both HbAlc And total haemoglobin are determined the $\mathrm{HbA1c} /$ Total haemoglobin is expressed as $\%$ HbA1c.HbA1c is determined by immune inhibition test.

3. Lipid profile- Total cholesterol, Triglycerides, HDL, LDL Triglyceride Enzymatic color test was the principal for serum Triglyceride estimation

Total Cholesterol - Enzymatic color test using cholesterol esterase and cholesterol oxidase was done for quantitative determination of cholesterol in serum.

HDL - Anti Human Beta lipoprotein antibody in reagent 1 binds to lipoproteins other than HDL. The antigen antibody complexes formed blocks enzyme reaction when reagent 2 is added. DL cholesterol is identified by the presence of an enzyme chromosome system.

LDL- A protecting agent in reagent 1 protects LDL from enzymatic reactions all non lal lipoproteins are broken down by reaction with cholesterol esterase and cholesterol oxidase.

$\mathrm{H} 2 \mathrm{O} 2$ produced by this reaction is decomposed by catalase. When Reagent 2 is added the protecting 
agent is released from LDL and catalase inactivated by sodium azide.LDL can now be quantified by cho/pap system.

4. Urea - Urea is hydrolysed in the presence of water and urease to produce ammonia and carbon dioxide the ammonia produced in the first reaction combines with 2 oxoglutarate and NADH in the presence of Glutamate dehydrogenase to yield glutamate and NAD+.Decrease in NAD absorbance per unit time is proportional to urea concentration.

Creatinine - Creatinine forms a yellow orange colored compound with picric acid in an alkaline medium. Rate of change in absorbance at 520/800 $\mathrm{nm}$ is proportional to creatinine concentration in the sample.

5. Microalbumin_- This is based on the principal of immune turbidimetry. Urine microalbumin when a sample is mixed with tris buffer and goat anti human albumin antibody human albumin reacts specifically with anti human antibody to yield in soluble aggregates. The absorbance of these aggregates is proportional to the albumin concentration in the sample.

6. Urine $\mathrm{r} / \mathrm{m}$

7. Urine $\mathrm{c} / \mathrm{s}$

8. ACR

9. TSH

\section{Analysis of Data}

Data were processed in Excel-sheet and analyzed using the SPSS software (version 11.5). Quantitative variables were summarized using mean and standard deviation while categorical variables were tabulated using frequencies and percentages. Student's t-test was used for testing the significance of differences between the mean values of two continuous variables. The probability (p) level of less than 0.05 was considered significant. Logistic regression was used to examine predictors of neuropathy, nephropathy, and retinopathy using variables
Type 2 diabetes mellitus duration, Hypertension Duration, Systolic blood pressure, Diastolic Blood Pressure As independent variables

\section{Result}

Out of 126 patients about $4 \%$ were $<40$ years of age, maximum number of patient belonged to age group $41-60,64 \%$ and only $32.6 \%$ patient were in elderly group. Mean age was found to be $56.67 \pm 8.38$. Majority of females fell in the age group of $41-60$ years $(76.59 \%)$. Whereas age distribution was almost equal in men and women in 41-60.In both male and female age group only $2.53 \%, 6.38 \%$ were noted to be $<40$ years of age respectively. $\mathrm{p}$ value $=<.001$, Which is statistically significant. The difference between male and female was found to be highly significant $(\mathrm{p}<0.001)$ Around $28.58 \%$ patient were non obese .In our study majority of patient were found to be obese (50\%) and $21.42 \%$ were observed to be overweight. Most of our patient were found to be obese (with BMI 25.22 \pm 3.73 ) according to the WHO guidelines and the consensus statement for diagnosis of Obesity, Abdominal obesity and the metabolic syndrome for Asian Indians. (Normal BMI: 18-22.9 kg/m2; Overweight: $22-24.9 \mathrm{~kg} / \mathrm{m} 2$;Obesity : > 25 $\mathrm{kg} / \mathrm{m} 2$ ). Most of the patients were obese. Overweight patient constituted $26.65 \%$ male and $12.76 \%$ female. Almost equal number of diabetic males $(27.58 \%)$ as well as females $(29.78 \%)$ were having normal BMI. p value $<0.04$. The difference between male and female was found to be significant $(\mathrm{p}<0.04)$. Male patient having central obesity (55\%) exceeded males with normal $(45 \%)$ abdominal circumference. In females majority of them were having central obesity and only $6 \%$ females were having normal abdominal girth. Mean waist circumference among females was $92.03 \pm 9.85$. In comparison more than $90 \%$ of female were found to be having central obesity, whereas about half $(55 \%)$ of males revealed abdominal obesity .Good number of males (45\%) were normal around the waist .only $6.38 \%$ female were having normal abdominal girth. $\mathrm{p}$ value 
$<.001$. The difference between male and female was found to be highly significant $(\mathrm{p}<0.001)$. More than half $(55 \%)$ of our population were having cholesterol within normal limit. Around 60 $\%$ of diabetic patient revealed normal triglyceride level. Only $41 \%$ diabetic showed raised triglyceride level. Out of 126 patients very few diabetics $(15 \%)$ were having normal HDl. Majority were having low HDL. LDL was well within control in $86 \%$ of patients with 82 out of 126 patients LDL less than/equal to $100 \mathrm{mg} / \mathrm{dl}$. About $69 \%$ of total diabetic were suffering from hypertension. Significant percentage of females were found to be having dyslipidemia (91\%), whereas about $79 \%$ of males were having abnormal lipid profile. The difference between male and female was found to be significant $(p<0.03)$. In our study it was observed that approximately $70 \%$ of patients were having Metabolic syndrome and on comparing between male to female percent it was seen that female patient were predominantly suffering from metabolic syndrome. The difference between male and female was found to be highly significant $(\mathrm{p}<0.001)$

Out of 126 patients 15 patients were having hypothyroidismIn present study good glycemic control was achieved in $34.17 \%$ of males but only $21.27 \%$ of females revealed good control .Equal number of male and females had glycated haemoglobin between $7-9 \%$ More than $51 \%$ of females and about $39 \%$ of males showed HbA1C above $9 \%$.p value 0.1 . The difference between male and female was found to be not significant $(\mathrm{p}<0.1)$.

Out of 126 patients $45.56 \%$ males and $44.68 \%$ females were having diabetic neuropathy

Approximately one third (27\%) of males and twenty percent females had retinopathy. The difference between male and female was found to be not significant ( $p$ value 0.17). One fourth of males $26 \%$ and about one fifth of females had nephropathy. Kidney involvement was seen in only $23 \%$ of patients .The difference between male and female was found to be not significant ( $p$ value 0.3).In present study out of 126 patients 17 $\%$ patient were suffering from coronary heart disease.

In our hospital study although conducted in small number of patients revealed:

1. Most of the patients belonged to age group 40-60.

2. Majority of diabetics were obese, having BMI more than $25 \mathrm{~kg} / \mathrm{m} 2$.

3. Very few new patients were studied in our study presenting with polydipsia, polyuria as common presentation.

4. Majority of our patients were having dyslipidemia, and it was seen that dyslipidemia was significantly preponderant in females.

5. There was dominance of female having metabolic syndrome almost reaching $91 \%$ which is much above the findings depicted by other Indian studies, Probably because of limited number of females in our study.

6. Our study revealed the level of glycemic control was near the target given by ADA in almost one third of patients, which can be attributed to comprehensive care imparted by endocrinology unit.

7. Neuropathy, Retinopathy and Nephropatahy, were present in one fourth of the patient and it was seen to be significantly associated with duration of diabetes.

Further study with large number of patient is required to substantiate our study. 


\section{JMSCR Vol||04||Issue||04||Page 10305-10322||April}

Body mass index

\begin{tabular}{|l|c|c|}
\hline \multicolumn{1}{|c|}{ RANGE(Kg/m2) } & NO OF PATIENTS & PERCENTAGE \\
\hline$\bullet 18.5-22.9$ & 36 & $28.58 \%$ \\
$\bullet 23-24.9$ & 27 & $21.42 \%$ \\
$\bullet>25$ & 63 & $50 \%$ \\
\hline
\end{tabular}

\section{Male Female BMI distribution}

\begin{tabular}{|l|c|c|c|c|}
\hline \multicolumn{1}{|c|}{ BMI } & Male No & $\%$ & Female No & $\%$ \\
\hline$<=23$ & 22 & 27.8 & 14 & 29.78 \\
\hline $23.1-24.9$ & 21 & 26.65 & 6 & 12.76 \\
\hline$>25$ & 36 & 45.55 & 27 & 57.44 \\
\hline
\end{tabular}

\section{Waist Circumference Male}

\begin{tabular}{|c|c|c|c|}
\hline Waist circumference & NUMBER & MEAN \pm S.D & PERCENTAGE \\
\hline$\bullet<=90$ & 36 & $90.5 \pm 8.20$ & $45 \%$ \\
$\bullet>90$ & 43 & & $55 \%$ \\
\hline
\end{tabular}

\section{Lipid profile}

Total cholesterol

\begin{tabular}{|c|c|c|}
\hline Total cholesterol & No & $\%$ \\
\hline$<=170$ & 70 & 55 \\
\hline$>170$ & 57 & 45 \\
\hline
\end{tabular}


Triglyceride Level

\begin{tabular}{|c|c|c|}
\hline Triglyceride & No & $\%$ \\
\hline$<=150$ & 74 & 59 \\
\hline$>150$ & 52 & 41 \\
\hline
\end{tabular}

$\underline{\text { HDL }}$

\begin{tabular}{|c|c|c|c|c|}
\hline Total & Low & $\%$ & Normal & $\%$ \\
\hline 126 & 107 & $85 \%$ & 20 & $15 \%$ \\
\hline
\end{tabular}

\section{LDL Level}

\begin{tabular}{|c|c|c|}
\hline Ldl level & No & $\%$ \\
\hline$<=100$ & 82 & 66 \\
\hline $101-130$ & 26 & 20 \\
\hline$>130$ & 18 & 14 \\
\hline
\end{tabular}

\section{Metabolic svndrome}

\begin{tabular}{|l|c|c|c|c|}
\hline & Present & $\%$ & Absent & $\%$ \\
\hline Male & 45 & 56.96 & 34 & 43.04 \\
\hline Female & 43 & 91.48 & 4 & 8.52 \\
\hline Total & 88 & 69.84 & 38 & 30.16 \\
\hline
\end{tabular}

Hypothyroidism in Type 2 diabetes

\begin{tabular}{|c|c|c|c|c|}
\hline Total & Present & $\%$ & Absent & $\%$ \\
\hline 126 & 15 & $12 \%$ & 111 & $88 \%$ \\
\hline
\end{tabular}


$\underline{\text { Logistic Regression Nephropathy }}$

\begin{tabular}{|l|l|l|l|l|}
\hline & \multicolumn{1}{|c|}{ B } & \multicolumn{1}{c|}{ Wald } & \multicolumn{1}{|c|}{ Sig } & \\
\hline DM Dur & -0.73 & 4.144 & .042 & S \\
HTnDur & -0.62 & 2.618 & .106 & Ns \\
SBP & 0.001 & .007 & 1.001 & Ns \\
DBP & -0.014 & .102 & .986 & Ns \\
Constant & 3.090 & 962 & 21.975 & Ns \\
\hline
\end{tabular}

The logistic regression analysis reveals significant association between duration of diabetes and nephropathy. ( $\mathrm{p}$ value 0.042 )

\section{Logistic Regression Table_Retinopathy}

\begin{tabular}{|l|l|l|l|l|}
\hline & \multicolumn{1}{|c|}{ B } & \multicolumn{1}{c|}{ Wald } & \multicolumn{1}{c|}{ Sig } & \\
\hline DM Dur & -.105 & 7.864 & .005 & S \\
HTnDur & .022 & .332 & .565 & Ns \\
SBP & -.007 & .192 & .661 & Ns \\
DBP & .005 & .016 & .901 & Ns \\
Constant & 1.454 & .289 & .591 & Ns \\
\hline
\end{tabular}

There is strong association between duration of diabetes and retinopathy. ( $p$ value $0.005)$

\section{Logistic Regression Table Neuropathy}

\begin{tabular}{|l|l|l|l|l|}
\hline & \multicolumn{1}{|c|}{ B } & \multicolumn{1}{|c|}{ Wald } & \multicolumn{1}{|c|}{ Sig } & \\
\hline DM Dur & 0.149 & 12.197 & 0.000 & S \\
HTnDur & -0.002 & 0.003 & 0.957 & Ns \\
SBP & -0.013 & 0.545 & 0.460 & Ns \\
DBP & -0.012 & 0.87 & 0.770 & Ns \\
Constant & 1.411 & 0.215 & 0.649 & Ns \\
\hline
\end{tabular}

Highly significant association is seen between duration of diabetes and neuropathy. (p value 0.005 ) 
Distribution of clinical and other associated factors of Type 2 Diabetes Patien from BGH, Bokaro

\begin{tabular}{|c|c|c|}
\hline CHARACTRISTICS & NUMBER(T $=126)$ & Percent $\%$ \\
\hline $\begin{array}{l}\text { Age(years)(means } \pm \text { s.d) } \\
\text { Weight kg(mean) }\end{array}$ & $\begin{array}{l}56.67 \pm 8.38 \\
65.89 \\
\end{array}$ & \\
\hline $\begin{array}{l}\text { AGE GROUP } \\
<=40 \\
41 \cdot 60 \\
>60\end{array}$ & $\begin{array}{l}5 \\
80 \\
41 \\
\end{array}$ & $\begin{array}{l}4 \% \\
63 \% \\
33 \% \\
\end{array}$ \\
\hline $\begin{array}{l}\text { SEX } \\
\text { Male } \\
\text { Female } \\
\end{array}$ & $\begin{array}{r}79 \\
47 \\
\end{array}$ & $\begin{array}{l}63 \% \\
37 \% \\
\end{array}$ \\
\hline $\begin{array}{l}\text { Glycosylated haemoglobin } \\
\text { (HbA1c) (mean } \pm \text { SD) } \\
\text { Glycaemic status (\%) } \\
<7 \text { (good control) } \\
7 \cdot 9 \text { (sub-optimal control) } \\
>9 \text { (uncontrolled) }\end{array}$ & $\begin{array}{l}9.55 \pm 3.42 \\
\\
37 \\
34 \\
55 \\
\end{array}$ & $\begin{array}{l}29 \% \\
27 \% \\
44 \% \\
\end{array}$ \\
\hline $\begin{array}{l}\text { BMI group } \\
\text { Normal }\left(18.5-22.9 \mathrm{~kg} / \mathrm{m}^{2}\right) \\
\text { Overweight }\left(23.0-24.9 \mathrm{~kg} / \mathrm{m}^{2}\right) \\
\text { Obese }\left(\geq 25.0 \mathrm{~kg} / \mathrm{m}^{2}\right)\end{array}$ & $\begin{array}{l}36 \\
27 \\
63 \\
\end{array}$ & $\begin{array}{l}29 \% \\
21 \% \\
50 \% \\
\end{array}$ \\
\hline $\begin{array}{l}\text { Metabolic syndrome } \\
\text { Male } \\
\text { Female }\end{array}$ & $\begin{array}{l}88 \\
45 \\
43\end{array}$ & $\begin{array}{l}70 \% \\
57 \% \\
91 \%\end{array}$ \\
\hline $\begin{array}{l}\text { Dyslipidaemia } \\
\text { Male } \\
\text { Female }\end{array}$ & $\begin{array}{l}107 \\
63 \\
43\end{array}$ & $\begin{array}{l}85 \% \\
79 \% \\
91 \%\end{array}$ \\
\hline Hypothyroidism & 15 & $12 \%$ \\
\hline Hypertension & 87 & $69 \%$ \\
\hline CHD & 22 & $17 \%$ \\
\hline Nephropathy & 29 & $23 \%$ \\
\hline Neuropathy & 57 & $45 \%$ \\
\hline Retinopathy & 30 & $24 \%$ \\
\hline
\end{tabular}

\section{Discussion}

Type 2 diabetes mellitus is a major public health problem and has become disease of paramount importance, it is the sixth leading cause of death and results in significant morbidity .India is no exception to this and very soon going to become Diabetic capital surpassing china (Mohan v et al). This study presented cross sectional data from subjects with type 2 diabetes attending Department of endocrinology, Bokaro General Hospital, Jharkhand. So far as we know very few studies have been done in the state of Jharkhand. Abundant literature is available from various part of India such as New Delhi, Chennai, Hyderabad, Gujarat etc. Recent studies from India showed increasing prevalence of type 2 diabetes in all the regions like $19.5 \%$ in Kerala (ADEPS), $15.5 \%$ in Chennai (CURES), $13.5 \%$ Chennai, 12.4\% in Bangalore,
$16.6 \%$ in Hyderabad, $11.7 \%$ in Kolkata and $9.3 \%$ in Mumbai (NUDS). Our prime aim was to find out the anthropometric, clinical and biochemical profile of diabetes and associated complications in patients who hail from industrial township of Bokaro steel city.

Type 2 Diabetes mellitus occurs most commonly in adults aged 40 years or older, and the prevalence of the disease increases with advancing age, Indeed the aging of the population is one reason that type 2 diabetes mellitus is becoming increasingly common, Virtually all cases of diabetes mellitus in older individual are type 2.In the present studytype2 diabetic subjects were evenly distributed in three age groups with a mean age of $56\} 8$ years. The study sample comprised of $(\mathrm{n}=126), 62.69 \%(79)$ males and $37.31 \%(47)$ females. In our study most of our patient belonged 
to age group $41-60$ years $(63.44 \%)$ which is consistent with the study conducted by JC et al . Overweight, excess energy intake and physical inactivity has been associated with the rapidly rising number of diabetes in India. Majority of our patients were found to be obese $(50 \%)$ having BMI $>25 \mathrm{~kg} / \mathrm{m} 2$, only $21 \%$ were observed to be having normal BMI . Overweight patients comprised approx. $27 \%$ of our study. The findings showed the mean BMI of $25.22 \square\} 3.73$. So in total more than $75 \%$ of our total patients were above normal BMI. According to Misra A et al almost $30-65 \%$ of adult urban Indians are either overweight or obese or have abdominal obesity, which is similar to our series. Mayur Patel et al (Gujrat) found that there diabetic patients had a mean BMI of 27.06 4 4.57, which is in conformity with our finding (25.22 33.73). Similarly in various studies by Singhet al, Shai et al, Misra A et al (2008) showed that overweight/obesity and central obesity were significantly associated with diabetes. Waist circumference is a powerful indicator of metabolic diseases. We observed that $>93 \%$ of our female subjects were having abdominal girth of $>80 \mathrm{~cm}$; in males also $>55 \%$ were having central obesity, Which is consistent with the finding of Chopra et al ,Delhi Where they concluded that $>90$ $\mathrm{cm}$ in males and above $>80 \mathrm{~cm}$ in females is a powerful clinical predictor of the metabolic syndrome. In a study conducted by Reddy et al $30.9 \%$ of men and $32.8 \%$ of women in industrial population in India were reported to have abdominal obesity, Gupta et al in his study noted $44 \%$ of females and $21.8 \%$ of males having central obesity but he used old criteria $(w c=>102 \mathrm{~cm}$, Male, $>=88 \mathrm{~cm}$ in Females), Prabhakaran et al revealed in his study of industrial population in North India that $10.1 \%$ of males were having central obesity and $25.9 \%$ of females showed increased abdominal girth applying criteria for south east Asian. Our findings are at variance with that of Prabhakaran et al who has given his finding on industrial population as we have .The dissimilarity is probably because of small number of patients in our series. One point of note is that females exceed male while considering central obesity in all the studies. Moreover these are population study conducted in general population. Although our study comprised of very few new type 2 diabetes subjects(7\%) it revealed that most common presentation were polyuria, polydipsia, nocturia, some patients presented with weight loss as well. Similar observations were seen in Mayur et al (Gujrat) and other sources . As stated by Gupta R et al : Metabolic syndrome was present in 345 (31.6\%) age-adjusted prevalence was $24.9 \%$, $18.4 \%$ in men and $30.9 \%$ in women. Misra et al in their population study done in North India showed $13.3 \%$ in male and $15.6 \%$ female to be having metabolic syndrome where as Deepa et al found (urban) $23.2 \%$ of patient suffering from metabolic syndrome. Ramchandran et al (2003), revealed $36.4 \%$ male and $46.5 \%$ female to be having mets, which clearly shows female with mets exceeding males . Chow et al found $32.5 \%$ and $23.9 \%$ male and female respectively which is at variance with our study. Mets is highly prevalent in the urban Indian diabetic population. It should be identified by regular screening in individuals from the general population to avert or delay the progression to type 2 diabetes in order to reduce diabetes- related morbidity and mortality . In our study $12 \%$ of diabetic patients were having hypothyroidism, which shows association of hypothyroidism with type 2 diabetics . Diabetic patients have a higher prevalence of thyroid disorders compared with normal population .A number of studies have also indicated a higher than normal prevalence of thyroid disorders in type 2 diabetic patients, with hypothyroidism being most common disorder. Hypothyroidism to be nearly 6 percent among people with type 2 diabetes, compared to just under 2 percent in those without. In various studies it was seen that the association between type 2 diabetes and hypothyroidism was so significant that researchers recommended routine screening for hypothyroidism at the time of a type 2 diabetes diagnosis. As stated by Sweresh et al Hypertension is approximately twice as frequent in patients with diabetes compared with 
patients without the disease. Conversely, recent data suggest that hypertensive persons are more predisposed to the development of diabetes than are normotensive persons. Hypertension is very common in diabetes. The people with type 2 diabetes mellitus tends to be older, Hypertension defined as blood pressure of $140 / 90 \mathrm{mmHg}$, is twice common versus the aged matched nondiabetic population, affecting approximately $80 \%$ of people with type 2 diabetes.

In present study two third of the patients were found out to be hypertensive, which is consistent with the statement by Sweresh et al. In our series $17 \%$ of patients were noted to be having coronary artery disease. In our study $45 \%$ of patients were having neuropathy. The EURODIAB study found prevalence rate of $28 \%$ for Diabetic neuropathy.In present study prevalence of neuropathy was higher . In our study diabetic retinopathy was found in 24 $\%$ of patients and its association with type $2 \mathrm{dm}$ duration was found to be significant $(\mathrm{p}$ <.005). Which is consistent with the Wisconsin Epidemological study of Diabetic retinopathy (WESDR) Statement, that Prevalence of retinopathy and Maculopathy increases with the duration of diabetes.In various studies on the prevalence of diabetic retinopathy was found as Remaet al, 1996 Clinical based (Chennai) $34.1 \%$, Dandonaet al 22.6\% Ramachandranet al, $23.7 \%$, Remaet al, 2000 Chennai $7.3 \%$ Narendran et al, $200226.8 \%$ which is quite similar with our study. In present study nephropathy was present in $23 \%$ of subjects. Significant association was observed between duration of diabetes with development of nephropathy $(\mathrm{p}<0.042)$. The prevalence of nephropathy In various studies atIndia like Gupta et al, (1991) Clinical based New Delhi Microalbuminuria: 26.6\%, Yajniket al, (1992) Clinic based Pune Microalbuminuria: 23.0\%, Vijay et al, (1994)Clinical based Chennai Proteinuria: 18.7\%, Varghese et al, (2001)Clinical based Chennai Microalbuminuria: $36.3 \%$, Unnikrishnanet al, (2006) Population based Chennai Microalbuminuria : $26.9 \%$, which is similar to our study.
Studies have documented that self-care among T2DM subjects improved glycaemic control and reduced complications. In the present study, 29.3\% of the subjects had good glycaemic Control ( $<7 \%)$ which was similar to various studies. A Swedish survey found that $34 \%$ of type 2 diabetes subjects had good glycaemic control. Al- Maskari F et al. found that $38 \%$ of T2DM subjects had good glycaemic control, and the study by Al-Kaabi $\mathrm{J}$ et al. reported that $31 \%$ of subjects had good glycaemic control. The reason of good glycemic control can be attributed to comprehensive care taken by our endocrinology unit. Raheja Bs et al. in his study (DIABCARE asia India study) which was intended to investigate the relationship between diabetes control, management and late complications in a subset of urban Indian diabetes population treated at 26 tertiary diabetes care centres. A total of 2,269 patients participated in this study and it was observed that approximately half the patients had poor control (HbA1c > 2\% points above upper limit of normal) and mean HbA1c was significantly higher (8.9\} 2.1\%) than the levels recommended by the American Diabetes Association and the ICMR guidelines in India. Poor glycemic control (HbA1c >7\%) was present in $65.1 \%$ of patients. In Kuwait, $66.7 \%$ of the studied population had $\mathrm{HbAlc} \geq 8 \%$ (Al-Sultan \& Al-Zanki, 2005). In Saudi Arabia, only 27\% of the patients reached target level of glycemic control (Akbar, 2001). In Pakistan (Habib \& Aslam, 2003), $46.7 \%$ of patients had HbA1c $>7.5 \%$. In Trinidad, $85 \%$ had HbA1c $>7 \%$ (Ezenwaka \& Offiah, 2001). Furthermore, HbA1c reported from National Health and Nutrition Examination Survey III was $>9 \%$ in $24.5 \%$ of patients (Saaddine et al., 2006). In UK, 69\% had HbA1c >7.5\% (Fox, Gerber, Bolinder, Chen, \& Kumar, 2006). All the above mentioned studies clearly reveal the difficulty in attaining ideal glycemic control.

\section{Conclusion}

In our hospital study although conducted in small number of patients revealed: 
1. Most of the patients belonged to age group 40-60.

2. Majority of diabetics were obese, having BMI more than $25 \mathrm{~kg} / \mathrm{m} 2$.

3. Very few new patients were studied in our study presenting with polydipsia, polyuria as common presentation.

4. Majority of our patients were having dyslipidemia, and it was seen that dyslipidemia was significantly preponderant in females.

5. There was dominance of female having metabolic syndrome almost reaching $91 \%$ which is much above the findings depicted by other Indian studies, Probably because of limited number of females in our study.

6. Our study revealed the level of glycemic control was near the target given by ADA in almost one third of patients, which can be attributed to comprehensive care imparted by endocrinology unit.

7. Neuropathy, Retinopathy and Nephropatahy, were present in one fourth of the patient and it was seen to be significantly associated with duration of diabetes. Further study with large number of patient is required to substantiate our study

\section{References}

1. Epidemiology of type 2 diabetes: Indian scenario. Mohan V, Sandeep S, Deepa R, Shah B, Varghese C. PMID: 17496352[PubMed - indexed for MEDLINE] Indian J Med Res.2007 Mar;125(3):217-30._ )

2. CDC 2003, National Diabetes fact sheet, www.cdc.gov/diabetes/factsheet.htm.

3. Ebrahim S, Kinra S, Bowen L, Andersen E, Ben-Shlomo Y, Lyngdoh T et al. The effect of rural-to-urban migration on obesity and diabetes in India: a crosseectionalstudy. PLoSMed2010;7(4):e1000268(doi:10.137 1/journal.pmed.1 000268).
4. Mohan V, Deepa M, Deepa R, Shanthirani CS, FarooqS, Ganesan A et al. Secular trends in the prevalence of diabetes and impaired glucose tolerance in urban south India-the Chennai urban rural epidemiology study (CURES-17). Diabetalogia 2006;49:1175-8.

5. Deepa M, Pradeepa R, Rema M, Mohan A, Deepa R, Shanthirani S, Mohan V. The Chennai urban rural epidemiology study (CURES) - study design and methodology (urban component) (CURES-I). J Assoc Physicians India 2003;51:863-70.

6. Misra A, Khurana L. The metabolic syndrome in South Asians: epidemiology, determinants, and prevention. Metab Syndr RelatDisord2009; 7:497-514.

7. (Boden G. Fatty acids and insulin resistance. Diabetes Care. Apr 1996;19(4):394-5)

8. (Bacha F, Lee S, Gungor N, Arslanian SA. From pre-diabetes to type 2 diabetes in obese youth: pathophysiological characteristics along the spectrum of glucose dysregulation. Diabetes Care. Oct 2010;33(10):2225-31) .

9. (Hansen KB, Vilsboll T, Bagger JI, Holst JJ, Knop FK. Increased postprandial GIP and glucagon responses, but unaltered GLP-1 response after intervention with steroid hormone, relative physical inactivity, and high-calorie diet in healthy subjects. J ClinEndocrinolMetab. Feb 2011;96(2):447-53).

10. (Krssak M, Winhofer Y, Gobl C, et al. Insulin resistance is not associated with myocardial steatosis in women. Diabetologia. Jul 2011;54(7):1871-8).

11. (Leiter LA, Lundman P, da Silva PM, et al. Persistent lipid abnormalities in statintreated patients with diabetes mellitus in Europe and Canada: results of the Dyslipidaemia International Study. Diabet Med. Nov 2011;28(11):1343-1351). 
12. http://www.who.int/mediacentre/factsheets /fs312/en/

13. Mohan v et al Indian J Med Res 125, March 2007, pp 217-230

14. Rao PV, Ushabala P, Seshaiah V, Ahuja MMS, Mather HM. The Eluru survey: prevalence of known diabetes in a rural Indian population

15. Alberti et al the metabolic syndrome - a new world wide definition the lancet 2005 , 1059-1062

16. Cameron aj saw prevalence in worldwide population endocrinology and metabolism clinic of north America 2004,351-375

17. Lee wy, jungCH, parjjs, rhee, EJkim e10,11

18. olufadi R, Byrne CD. Clinical and laboratory diagnosis of the metabolic syndrome. J ClinPathol. Jun 2008;61(6):697-706

19. Grundy SM, Cleeman JI, Daniels SR, et al. Diagnosis and management of the metabolic syndrome: an American Heart Association/National Heart, Lung, and Blood Institute Scientific Statement. Circulation. Oct 25 2005;112(17):2735-52.

20. Prevalence of Metabolic Syndrome in An Urban Indian Diabetic Population Using The NCEP ATP III Guidelines SP Surana*, DB Shah ,Japi .org:

21. Prevalence of metabolic syndrome in an Indian urban population. Gupta $\mathrm{R}$ et al, source : pubmed

22. Dyslipidemia in type 2 diabetes mellitus ,PUBMED, Mooradian et al Nat clinpract endocrinology metabolism 2009 mar ;5(3):150-9 1.

23. Malik S, Wong ND, Franklin SS, et al. Impact of the metabolic syndrome on mortality from coronary heart disease, cardiovascular disease, and all causes in United States adults. Circulation 2004; 110: 1245-50.Lakka HM, Laaksonen DE,

24. Lakka TA, et al. The metabolic syndrome and total and cardiovascular mortality in middle-aged men .JAMA 2002; 288: 2709-16.

25. Abdel-Aal

NMhttp://www.ncbi.nlm.nih.gov/pubmed? term=AbdelAal\%20NM\%5 BAuthor\%5D $\&$ cauthor=true \&cauthor_uid $=18946566$

26. World Health Organization. Obesity: preventing and managing the global epidemic. Report of a WHO consultation presented at: theWorld Health Organization; June 3-5, 1997;Geneva, Switzerland. Publication WHO/NUT/ NCD/98.1.

27. Misra A, Khurana L. Obesity and the metabolic syndrome in developing countries. J Clin Endocrinol Metab 2008;93(11Suppl1):S930.

28. Mayer-Davis EJ, Costacou T. Obesity and sedentary lifestyle: modifiable risk factors for prevention of type 2 diabetes. Curr Diabet Rep 2001;1:170-6.

29. Lieberman LS. Dietary, evolutionary, and modernizing influences on the prevalence of type 2 diabetes. Annu Rev Nutr2003;23:345-77.

30. Bener A, Al-Suwaidi J, Al-Jaber K, Al-Marri S, Elbagi IE. Epidemiology of hypertension and its associated risk factors in the Qatari population. J Hum Hypertens2004;18:529-30.

31. Musaiger AO, Al-Mannai MA. Social and lifestyle factors associated with diabetes in the adult Bahraini population. $\mathbf{J}$ BiosocSci2002;34:277-81.

32. Gupta R, Gupta VP, Sarna M, et al. Prevalence of coronary heart disease and risk factors in an urban Indian population: Jaipur Heart Watch-2.Indian Heart J 2002;54(1):59-66.

33. Gupta R, Gupta VP, Sarna M, et al. Prevalence of coronary heart disease Gupta R,Misra A. Type 2 diabetes in India: Regional Disparities. $\mathrm{Br} \mathrm{J}$ Diabetes \& Vascular Dis 2007;7:12-16 
34. KGMM Alberti et al for the IDF Epidemiology Task Force Consensus Group: Lancet 366:1059, 2005.

35. Singh RB, Bajaj S, Niaz MA, Rastogi SS, Moshiri M. Prevalence of type 2 diabetes mellitus and risk of hypertension and coronary artery disease in rural and urban population with low rates of obesity. Int $\mathrm{J}$ Cardiol1998 ;66:65-72..

36. (ref: feb 2009 issue of journal of clinical endocrinology and metaboloism jcem.endojournals.org)

37. Swersh et alHypertension. 2001 update Apr;37(4):1053-9. pubmed

38. http://www.annals.org/content/138/7/593.f ull\#ref-19

39. University of Milano-Bicocca, San Gerardo Hospital, Department of Clinical Medicine, Via Donizetti 106, I-20052 Monza, Milan, Italy. giuseppe. mancia@unimib.it.PMID: 15868115

[PubMed - indexed for MEDLINE]

40. UKPDS , Tight blood pressure control and risk of microvascular and macrovascular complications in type 2 diabetes ,BMJ,1998;317:703-1

41. From UKPDS group study 7 metabolism,1990 39 ,905-12

42. Oxford textbook of endocrinology second edition, 1774

43. Harris MI, Klein R, Welborn TA, Knuiman MW. Onset of NIDDM occurs at least 4- 7 yr before clinical diagnosis. Diabetes Care. Jul 1992;15(7):815-9

44. Ref: Raman $R$ et al ,ophthalmology ,2009,feb;116(2):311-8,Epub 2008 dec m2012, pmid 19084275.

45. RemaM,PremkumarS,AnithaB,.Prevalence of diabetic retinopathy in urban India CURES The Chennai urban epidemiology study .Invest opthalmolvis sci2005;46:232833

46. Varma $\mathrm{R}$,Torres $\mathrm{M}$,Latino eye study group prevalence of diabetic retinopathy in adults ,ophthalmology 2004,111,1298-306
47. The eye disease prevalence research group..The prevalence of diabetic retinopathy in adults in United states, Arch ophthalmol 2004;122:552-63

48. Ref:Trevisan $\mathrm{R} \quad$ walker,Diabetic nephropathy. In Jamison $\mathrm{R}$ willkinson $\mathrm{R} 2$ eds London chapman and hall,1997,551-574

49. Ref:Trevisan R walker, Diabeticnephropathy. In Jamison $\mathrm{R}$ willkinson R 2 eds London chapman and hall,1997,551-574

50. Mogensen CE ,definition of diabetic renal disease in IDDM based on renal function test 4th edition,1998, 17-30

51. Modified from National Kidney Foundation. K/DOQI Clinical Practice Guidelines for Chronic Kidney Disease: Evaluation, classification and stratification. Am J Kidney Dis 39:suppl 1, 2002.

52. Ramachandran A, Snehalatha C, Mary S, MukeshB, Bhaskar AD, Vijay V. Indian Diabetes Prevention Programme (IDPP): the Indian Diabetes Prevention Programme shows that lifestyle modification and metformin prevent type 2diabetes in Asian Indian subjects with impaired glucose tolerance

(IDPP-1).

Diabetologia2006;49:289-97.

53. Heisler M, Pietee JD, Spencer M, Kieffer E, Vijan S. The relationship between knowledge of recent HbA1c values and diabetes care understanding and self management. Diabet Care 2005;28:816-22.

54. (Holmstrom IM, Rosenqvist U. Misunderstandings about illness and treatment among patients with type 2 diabetes. J AdvNurs2005;49:146-54).

55. Maskari F, El-Sadig M. Prevalence of risk factors $\mathrm{n}$ for diabetic foot complications. BMC Fam Pract2007;8:59.),

56. (Al-Kaabi J, Al-Maskari F, Saadi H, Afandi B, Parkar H, Nagelkerke N. Assessmen of dietary practices among diabetic patients in 
the United Arab Emirates. Rev Diabet Stud 2008;5:110-5).

57. Rewers M, Hamman R. Risk factors for noninsulin- dependent diabetes. In: Harris MI, Cowie CC, Stern MP, Boyko EJ, Reiber GE, Bennett PH, eds. Diabetes in America. Bethesda, Md: National Institutes of Health; 1995. p. 179-220.

58. Mokdad AH, Ford ES, Bowman BA, et al. Prevalence of obesity, diabetes, and obesity related health risk factors, 2001. JAMA.2003;289(1):76-79.

59. Howard Bv Pathogenesis of diabetic dyslipidemia, Diabetes review 1995,3,423-432

60. Haaris MI hypercholesterolemia in diabetes and glucose intolerance in US people diabetes care $1991,366-374$

61. christleb AR Treatment selection consideration for the hypertensive diabetic patients, Arch intern med 1990,1167-1174

62. Brown wvhoward Treatment of lipoprotein disorder cardiovascclin 1990 ,157- 176

63. Howard WJ Brown WV Pharmacologic therapy of hypercholesterolemia curropincardiol $1989,525-541$

64. Howard BV robins DC sievers ML et al LDL cholesterol strong predictor of CHD in diabetic individuals with low LDL 2000;830-835

65. Howard BV ,Robbins DC, SieversML, et al, strong predictor of CHD, In diabetic individual with insulin resistance and low LDL, 2000;830-835

66. Tesfays S Boulton AJ eds. Diabetic neuropathy, oxford :oxford university press 2009

67. Shaw JE ,ZimmetPZ.The epidemiology of diabetic neuropathy Diabetes Rev 1999; 7:245-252

68. Tesfaye $S$,Stephens 1 ,Fuller J; et al; the EURODIAB IDDN complication study Diabetologia,1996,39:1377-84

69. TesfayeS, Chaturvedi N, Eaton SEM, Witte D, Ward JD, Fuller J VASCULAR RISK

\section{FACTORS}

AND

DIABETIC

NEUROPATHY NEJM 2005;352:341-50).

70. Watkins PJ, Edmonds ME, Clinical feature of diabetic neuropathy In pickup j williams, Textbook of diabetes Vol 2 oxford ,Blackwell science,1997:50.1-50.20)

71. World Health Organization. World Health Statistics. Department of Measurement \& Health Information Systems of the Information, Evidence and Research Cluster. Geneva: WHO Press; 2008. p. 29-31.592 INDIAN J MED RES, NOVEMBER 2010

72. Kannel WB. Some lessons in cardiovascular epidemiology from Framingham. Am J Cardiol1976; 37 : 269-82.

73. Yusuf S, Hawken S, Ounpuu S, Dans T, Avezum A, Lanas F, et al. Effect of potentially modifiable risk factors associated with myocardial infarction in 52 countries (the INTERHEART study): case-control study. Lancet 2004; 364 : 937-52.

74. Gupta R, Joshi P, Mohan V, Reddy KS, Yusuf S. Epidemiology and causation of coronary heart disease and stroke in India. Heart 2008; 94 : 16-26

75. Moss SE, Klein R, Klein BE. Cause-specific mortality in a population-based study of diabetes. Am J Public Health 1991; 81 : 1158-62.

76. Geiss LS, Herman WM, Smith PJ. Mortality in non-insulin-dependent diabetes. In: National Diabetes Data Group, editor. Diabetes in America, 2nd ed. Bethesda, MD: NIH \& NIDDK: National Diabetes Information Clearing house; 1995. p. 233- 55

77. Donahoe SM, Stewart GC, McCabe CH, Mohanavelu S, Murphy SA, Cannon CP, et al. Diabetes and mortality following acute coronary syndromes. JAMA 2007; 298 765-75. 
78. Stamler J, Vaccaro O, Neaton JD, Wentworth D. Diabetes, other risk factors, and 12-yr cardiovascular mortality for men screened in the Multiple Risk Factor Intervention Trial. Diabetes Care 1993; 16 : 434-44.

79. Franco OH, Steyerberg EW, Hu FB, Mackenbach J, Nusselder W. Associations of diabetes mellitus wth total life expectancy and life expectancy with and without cardiovascular disease. Arch Intern Med 2007; 167 : 1145-51.

80. Mohan V, Sandeep S, Deepa R, Shah B, Varghese C. Epidemiology of type 2 diabetes: Indian scenario. Indian J Med Res 2007; $125: 217-30$.

81. McKeigue PM, Ferrie JE, Pierpoint T, Marmot MG. Association of early-onset coronary heart disease in South Asian men with glucose intolerance and hyperinsulinemia. Circulation 1993; 87 : 152-61.

82. Enas EA, Mehta J. Malignant coronary artery disease in young Asian Indians: thoughts on pathogenesis, prevention, and therapy. Coronary Artery Disease in Asian Indians (CADI) Study. ClinCardiol1995; $18: 131-5$.

83. International Diabetes Federation (IDF). Diabetes atlas 4th ed. 2009. Available at: www.diabetesatlas.org.

84. Srikanth S, Deedwania P. Comprehensive risk reduction of cardiovascular risk factors in the diabetic patient: an integrated approach. CardiolClin2005; 23 : 193- 210.

85. Haffner SJ, Cassells H. Hyperglycemia as a cardiovascular risk factor. Am J Med 2003; 115 (Suppl 8A): 6S-11S
86. Reddy ks, Prabhakarn d,Chaturvedi v et al ,tm 2006 methods for establishing survillence system for cardiovascular disease in Indian industrial population: 84,461-469.

87. Raheja BS, Kapur A, Bhoraskar A, Sathe SR, Jorgensen LN, Moorthi SR, Pendsey S, Sahay BK. DiabCare Asia-India Study:diabetes care in India-current status. J Assoc Physicians India 2001;49:717-22 